\title{
A Promising Future for the Horticulture Profession
}

\section{Presidential Address of the ASHS Southern Region 62nd Annual Meeting, 2002}

\author{
M.P. Garber ${ }^{1}$ \\ Department of Horticulture, University of Georgia, Tifton, GA 31793
}

The future of our profession is incredibly promising based on any number of criteria. The U.S. demographics and societal trends suggests horticulture could play an important role in the future well-being of our society. That is great news because for the most part we will not have to buck a key trend or demographic change to be successful. My daughter would say we are "going with the flow". Horticulture is one of the few agricultural segments with sufficient product value to sustain profits without government assistance. This is not to imply that success or growth of our profession will be handed to us "on a silver platter". As a profession we will have to define and articulate our "fit" with society and work to maximize our value. This presentation is not an exhaustive listing of factors that could impact the future of our profession but rather highlights a few factors and discusses how we can capitalize on these trends.

Aging Population. The average age of the U.S. population is increasing. This is lead in part by the aging baby boom population. This population segment is entering their 50s and contributes to the increasing average age. Several factors that characterize this group have implications for Horticulture.

Health Conscious. Baby boomers are concerned about their health and eager to maintain personal health or prevent disease. They are particularly aware of and actively seek ways to prevent cancer. This has lead to an insatiable desire for information on prevention of cancer and other diseases. Therefore information on nutritional value and cancer preventing traits of fruits and vegetables, and other horticultural products, could have a pronounced effect on consumption patterns. For instance, consumption of foods with documented high levels of antioxidant activity is likely to increase. Horticulture faculty could partner with other disciplines to better understand the anti-cancer attributes of our products and then help educate the public. This should lead to a perception of higher value for horticultural products and hence higher prices and margins for industry clientele. However to be successful in this area, we must define the value/attributes of our products and educate consumers.

Life Expectancy. Life expectancy has increased in the United States and the Baby Boom generation definitely plans to live a long life. With this desire comes a keen sense of personal health, including eating the right food. The trend toward reduced consumption of high fat foods and greater consumption of nutritious foods should accelerate. This bodes

${ }^{1}$ Professor of Horticulture and Extension Specialist, Univ. of Georgia, P.O. Box 1209, Tifton, GA 31793. well for fruits and vegetables. To facilitate this trend, university and industry personnel could (1) identify and communicate nutritive value of horticultural products to consumers, (2) suggest horticultural products as substitutes for existing "junk" foods, (3) work with industry groups on directed marketing efforts to large institutional buyers (public and private) to get more horticultural products into the distribution chain i.e. target specific products to be replaced, and (4) capitalize on the international diversity of our profession to introduce new and more nutritious products to consumers. The focus of educational programs should be increased health for a longer happier life.

Disposable Income. The baby boom generation plans to have a high level of disposable income. Their children are becoming financially independent and most boomers plan to work, at least part-time during retirement. Admittedly some of the disposable income may disappear if the stock market continues a downward trend. Many current and near-term retirees have defined-benefit retirement plans that are less affected by economic cycles than the defined contribution plans. The relatively high and stable level of disposable income makes this population segment an important target audience for horticultural products and services. For instance, an aging generation with increased disposable income and limited time is likely to value services that free-up time for personal activities. This should lead to increased interest in horticultural services such as lawn maintenance. High levels of disposable income allows for quality enhancing landscape features such as water gardens and seasonal interest gardens.

Time for Self. The retiring baby boom generation and dual-career families value time for family and personal activities. For various reasons, most people prefer to minimize daily activities such as lengthy food preparation. This suggests an increasing interest in the current trend toward consumption of partially prepared or fully prepared foods that require a small investment of time. Mixing A and B together or heating the item in a microwave is about the level of involvement desired. However the consumer still desires the nutritive attributes that contribute to a long healthy life. This suggests a strong demand for fresh fruits and vegetables that can be quickly turned into a meal. This is a value-added opportunity for producers to vertically integrate through onsite processing of partially prepared items. However success requires a better understanding of the final use of fruits and vegetables by consumers so the value-added product can be targeted. This may require enhanced market research programs by university personnel.
Mental Health. The desire for a long healthy life includes attention to mental health. The baby boom generation and a large portion of the population understands that an active life style is important to a high quality of life. This is a great opportunity for horticultural gardening activities packaged as ways to enhance physical and mental health. Horticultural Therapy programs should be expanded to a larger segment of the population. The inevitable increase in nursing home population represents another important target audience. Our profession could lead efforts to ensure the highest quality mental health through horticultural programs tailored for institutional situations. We can partner with health care providers and educate the providers on horticultural therapy benefits for mental health and customer satisfaction.

Lifelong Learners. The U.S. population realizes that the changing world requires a life-long commitment to learning. This creates a natural customer base for a variety of traditional and nontraditional horticultural classes. This includes Master Gardener classes, special classes on main or branch campuses, and on-line classes. There is a growing interest in environmental or natural resource conservation topics and our profession is well trained to address such topics. The over 50 age group is rapidly increasing the amount of time spent on the world wide web and they will have plenty of time for on-line learning. We should identify ways to enroll special students so horticulture departments can increase state formula funding for teaching programs. Viable horticultural teaching programs in the future will require targeting of new audiences. We could increase our teaching support by leveraging consumer interest in gardening, natural resource conservation, increased discretionary time and money available to an aging population, and a desire for a healthy stimulating life-style. The good news is the baby boom generation plans to be around for a long time and could be great supporters of our industry and university programs.

Environmental Stewardship. Environmental preservation and natural resource management are important issues in today's society. During the first Earth Day it was considered radical to contemplate the fate of the Earth's natural resources. Today these issues are pressing community matters. What seemed extreme at the time has become mainstream due in large part to our growing population. Natural resource preservation will probably be an important societal issue for the foreseeable future. Therefore it should not be a surprise that consumers are interested in "naturalized landscapes' or 'habitat gardens'. In recent years habitat gardening has influenced plant 
material grown by nurseries and specified by landscape architects. Habitat Gardening includes Butterfly Gardens, Wildlife Habitat Gardens, Gardens that attract birds. Landscaping has diversified its purpose from strictly aesthetic to include objectives such as providing food and shelter for wildlife. The educational needs of the public are great in this area and university personnel are well positioned to be the primary supplier of unbiased research based information.

Environmental issues, such as clean air and clean water, require significant societal attention. Horticulture departments and industry have the products, information base, and technical skills to contribute in a significant manner. Addressing natural resource management issues will allow university professionals to work with traditional agricultural interests as well as the growing urban population.

For our profession to be a valuable resource for natural resource preservation, we may have to re-look the type of information provided. For instance it may not be sufficient to have publications listing plants for landscapes. Instead we need information developed around landscaping goals of the consumer, such as butterfly gardens. These publications will not only list plants but address how to group plants, and necessary non-plant material. The value of our information will be higher if we address how to solve a problem or capture an opportunity for the consumer. In the landscape area, this requires publications that are needs-based and not just a listing of plants that we think are "good".

Our profession is in a unique position to help meet the environmental goals of our society and, in the process, generate professional opportunities for those that participate. For instance, in the landscape area, we produce the products (plants) that assist with environmental enhancement and supply the services to achieve environmental landscape goals. To fully assist society and capitalize on the opportunities, we should consider more partnering with appropriate environmental groups. This partnership will help us identify environmental opportunities/needs of society and to focus application of scarce resources. In short we should get greater returns/recognition if we partner with environmental groups.

Horticulture: A Source of New and Exciting Products. The incredible array of new products introduced by the Horticulture profession should facilitate a robust industry. A strong university-industry partnership can introduce small refinements to existing products, such as new cultivars, or entirely new crops. Plant introduction is active in most horticultural commodities including ornamentals, vegetables, and fruits crops. The new products are readily identifiable by the end consumer which adds to the appeal of horticultural products. Many of the traditional agricultural crops do not have the quantity of new products and certainly not the visibility to the consumer. We could enhance our success with new product introductions by utilizing the international diversity of our membership to develop and introduce totally new plants that meet the health and environmental interests of the American consumer. This is an important element of the past success of the Horticulture profession and deserves increased resources and attention in the future.

The future demand for horticultural crops such as fruits and vegetables will increase in part due to the availability of fresh produce adjacent to major population centers. The ability to produce horticultural crops near the consumer is facilitated by the high value of horticultural products, which in-turn allows industry to accommodate high land prices near population centers. Also the quantity of land required is relatively small, compared to traditional row crops, due to the high density and high value per acre. Certainly some horticultural products will be produced remotely and even internationally. However, I project a strong future demand for locally produced fresh fruits, vegetables and ornamentals. This view is supported by the continued strong demand at local U-Pick operations.

Maximize our Value to Society. Although societal trends and demographics may favor our profession, we must be proactive to ensure success. Other groups will seek to benefit from the same trends and demographic changes and as such compete with our profession. Maximizing our value to society is the best way to take control of our future and ensure success. I suggest several steps to ensure our profession can capitalize on future opportunities.

Training in the Horticulture Field. We need to be skilled in our profession. A diverse undergraduate education that covers all commodities and cultural practices associated with the horticultural field prepares one to deal with varying future needs. The practical side of education should be complemented with a sound science-based training. We need enough science at the undergraduate level to deal with important fundamentals such as crop nutrition and plant growth and development. The science training provides greater professional flexibility including teaching at the high school or technical school level. Science training also provides the base skills to learn new and evolving technical information over a long career. In short, we need trained Horticulturists if we are to ensure continuation of our profession.

Diversification Training. The formal training in Horticulture opens the door to employment but, maximizing our contribution to industry and society requires additional skills. We should consider training in areas such as business management and ethics, development of public policy, and foreign language. These skills can be obtained during the traditional education period or as continuing education while working in the horticultural profession.

Training in business practices such as marketing, management, and finance is beneficial for many aspects of our profession. Undergraduates entering private industry will be able to contribute to the entire business operation and not just production practices. These students move more quickly into managerial positions with commensurate compensation. Business training is critical for the many stu- dents that plan to run their own business. This training can also benefit university faculty when dealing with clients regarding research or extension programs. Also most of our commodity type classes would benefit from an element of business management.

An understanding of how public policy is developed can be valuable to business owners, business managers, and university personnel working with public officials and industry clientele. Our business clients and profession do not exist in a public policy vacuum. We need to understand how the public policy system works if we are to develop and deliver good research- based information to guide policy development. It is important that our profession play a larger role in public policy development.

Demographics of the U.S. population dictate increased fluency in a second language and that language should be Spanish. We are also an international profession and our ability to capitalize on this diversity will be influenced by our understanding of other cultures, including their language. The work force in many horticultural operations is primarily Spanish-speaking and there is a need for supervisors proficient in this language. There are numerous consulting and educational opportunities in international horticulture where foreign language skills would be beneficial. Our profession should educate more Spanishspeaking students and encourage American students to learn the Spanish language.

Involvement in Interdisciplinary Projects. Interdisciplinary efforts are necessary to solve many of the complex horticultural issues. Horticulture professionals should be active participants. This will ensure that our expertise and insight as a profession is utilized to address emerging societal needs. We should always seek to apply our skills to the broadest and highest priority needs of society. This may require acquisition of new skills and venturing into new areas. These projects may range from Water Conservation in production and urban settings to Land-Use Planning. Although horticulturists are generally not involved in landuse planning, this issue will increase in importance with urbanization of our country. We have much to contribute to land use planning.

The Horticulture or Plant Science Department administrative officer has an important role in managing the balance of the above factors in the teaching, research and extension activities of their department. No single individual can address all of the items mentioned but a balanced department can address most of these. Hopefully, the mix of activities in the department will be the result of a conscious decision between faculty and administration and not merely left to chance.

Professional Philosophy. I offer two suggestions to guide personal development and professional objectives that should keep individuals and our profession relevant.

Take Risks. We should not avoid an important issue or project just because it "feels uncomfortable" or we can not guarantee success. To my university colleagues, remember that society established institutions such as 
universities to encourage risk taking or exploring new areas by minimizing the potential negative impact on faculty. Therefore university personnel should be leaders in risk taking. Perhaps we should avoid "comfort projects" done primarily because we know there is a high probably of obtaining publishable results. It is not unusual to make mistakes and if we share the experiences with others, we can help make our profession more dynamic and more productive.

Reinvent Yourself Every Five Years. I am not sure there is a magic frequency associated with this principle and it will vary with different areas of your program. However, it is important to continually review the important issues of society and our commercial clientele and change priorities accordingly. Identify yearly goals for new areas of focus and reinvent a percentage of your program each year. If we do not change and update the focus of our programs, we risk losing public and private support.

In summary, I am very optimistic about the future opportunities for our profession. If we are willing to listen to the needs of our commercial clientele and society and adjust our programs on a regular basis, we should be able to contribute to enhancement of our society. Continually updating and broadening our skills allows us to address complex societal issues. As such, we will become increasingly important to society and our profession and profession will grow.
References

Betz, C.J. and G.T. Green. 2002. Recreation and the environment as cultural dimensions in contemporary American society. Leisure Sciences 24(1):13-41.

Galarza, P., P. Regnier, and S. Rose. 2000. The best investments for 2000 and beyond. Money 29(1):70-76, 78 .

Sivy, M. 1997. Forecast: Having it all: What America will look like in 25 years. Money 26(10):98-102, 105-107.

Tufts University. 1998. Smarten up: Certain foods help maintain brain power as you age. Tufts University Health and Nutrition Letter 15 (12):4-5.

Brody, A.L. and J.B. Lord. 2000. Developing new food products for a changing marketplace. Technomic Pub. Co., Lancaster, Pa.

Christensen-Hughes, J. 1992. Cultural diversity: The lesson of Toronto's hotels. The Cornell hotel and restaurant administration quarterly 33(2):78-87.

Kinsey, J.D. 1992. Seven trends driving U.S. food demands. Choices: The magazine of food, farm and resource issues. 7(3):26-28.

\section{Abstracts of the ASHS Southern Region 62nd Annual Meeting}

\section{J.B. Edmond Undergraduate Competition}

\section{Sunflower to Municipal Solid Waste Compost Amended Media}

Viviana Baiz* and E.R. Emino, Dept. of Environmental Horticulture, Institute of Food and Agricultural Sciences, Univ. of Florida, Gainesville, FL 32611-0670

Sunflower (Helianthus annus L. 'Sunbright') grown in two commercial potting mixes amended with $0 \%, 25 \%, 50 \%, 75 \%$, or $100 \%$ (by volume) municipal solid waste (MSW)/biosolids co-compost grew as well as and in some cases better than the commercial controls. The purpose of this study was to determine the usefulness of MSW/ biosolids co-compost as a potting medium amendment. Sunflower seedlings were planted in the amended potting media in June 2001. They were harvested in August after growing in the greenhouse to full open flower and growth measurements made. Half the plants received a weekly application of $150 \mathrm{ppm}$ of 20-10-20 and the other half received only water during growth in the greenhouse. At harvest the following data were collected to assess plant growth and flower quality and subjected to statistical analysis: days to flower, height, flower disc diameter, total flower diameter, flower fresh weight, total plant fresh weight, flower dry weight, and total plant dry weight. The growth and quality parameters show the addition of compost to the potting mix either resulted in plants that were not different in plant growth or had enhanced plant growth and flower quality as compared to the controls. Further, the addition of compost to the potting mix did not have any negative effects in any of the parameters measured. The addition of fertilizer increased plant height and fresh and dry weights but did not affect days to flower and flower size measurements, which is consis- tent with previous reports on compost utilization that there are insufficient nutrients to sustain optimal plant growth. These result provide further evidence that plants can be grown successfully in MSW/ biosolids co-compost supplemented potting mix.

\section{Variability for Antioxidant Activity in Potato (Solanum tuberosum) as Influenced by Genotype and Storage}

Tyann Blessington, Anna L. Hale, and J. Creighton Miller, Jr., Dept. of Horticultural Sciences, Texas A\&M Univ., College Station, TX $77843-2133$

Antioxidants have a major impact on human health by reducing incidences of cancer, stroke, coronary heart disease, macular degeneration and high levels of LDL cholesterol. Potatoes are an important source of antioxidants since per capita consumption of potatoes in the United States is $\approx 145$ pounds. Several antioxidant compounds have already been identified in potatoes, and this can be used as a marketing tool to increase consumption. The objectives of this study were to evaluate the antioxidant activity of a broad range of potato genotypes; determine the effects of storage and harvest date on antioxidant activity; and identify potential parents for the TAMU breeding program. Tubers from named varieties and advanced selections from both early and late harvest near Springlake, Texas, were evaluated in 2001. A sample of tubers was stored for two months at $4.4{ }^{\circ} \mathrm{C}\left(40^{\circ} \mathrm{F}\right)$ and allowed to recondition for two weeks. Potato extracts from replicated tuber samples were used for the antioxidant assay. The assay involved use of 1,1-diphenyl-2-picrylhydrazyl (DPPH), which is a stable radical that absorbs at $515 \mathrm{~nm}$. This assay is an easy and rapid procedure to evaluate antiradical properties of the extract. Upon reduction, a decrease in absorbance is observed, i.e., greater absorbance of DPPH in the extract indicates a smaller amount of antioxidant activity. For comparison, standard curves were prepared with known concentrations of Trolox (6-hydroxy-2,5,7,8-tetramethylchroman-2-carboxylic acid), a widely used synthetic antioxidant. Significant differences were found for total antioxidant activity among genotypes in the early harvest, with Stampede Russet the highest and NDTX4304-1R the lowest. Few significant differences among genotypes were found in 